\title{
Gastrointestinal transit and prolonged ambulatory colonic motility in health and faecal incontinence
}

\author{
F Herbst, M A Kamm, G P Morris, K Britton, J Woloszko, R J Nicholls
}

\begin{abstract}
Background-Colonic motor function has not been studied in the ambulatory setting over a prolonged period in the unprepared state. Furthermore, the disturbance of this function in patients with faecal incontinence is unknown.

Aim-To study colonic function over two to three days in the ambulatory, unprepared state in health and in patients with idiopathic faecal incontinence.

Methods-Six healthy women and six women with faecal incontinence and a structurally intact anal sphincter ingested a dual radioisotope meal, and had a six sensor, solid state manometric probe colonoscopically inserted into the left colon. Scanning was performed until radioisotope left the gut and pressure was recorded for a median of 44 hours.
\end{abstract}

Results-Three of six patients showed abnormal gastric emptying. Patients showed no disturbance of colonic radioisotope transit. Controls had a median of 12 , whereas patients had a median of 16 , high amplitude propagated waves per 24 hours. In three patients urge incontinence was associated with high amplitude (up to $500 \mathrm{~cm}$ water) propagated waves which often reached the rectum. These high pressure waves were identical to those occuring in healthy subjects, the only difference being the lack of adequate sphincter response. Passive incontinence was not associated with colonic motor activity. Defaecation in all subjects was associated with identical propagated waves, and distal movement of $13 \%$ (median) of right colonic content and excretion of $32 \%$ from the left colon and rectum. The urge to defaecate was associated with either propagated waves $(45 \%)$ or non-propagated contractions (55\%). Rectal motor complexes were recorded in both groups of subjects, but similar rhythmic activity was also recorded in the sigmoid and descending colon.

Conclusions-Normal colonic function consists of frequent high pressure propagated waves. Rhythmic activity occurs both proximal to and in the rectum. Defaecation is characterised by high pressure propagated waves associated with coordinated anal sphincter relaxation. Patients with faecal incontinence may have a widespread disturbance of gut function. Urge incontinence, an urge to defaecate, and defaecation can all be asso- ciated with identical high amplitude propagated pressure waves.

(Gut 1997; 41: 381-389)

Keywords: colonic motility; gastric emptying; faecal incontinence

The maintenance of continence depends on the balance between bowel and anal sphincter function. Until now, most of the diagnostic interest in patients with incontinence has focused on the anal sphincter. Early studies established the presence of abnormal pudendal nerve function ${ }^{1}$ and electromyographic abnormalities $^{2}$ in many patients with faecal incontinence, with progressive weakness of the external sphincter believed to relate to denervation. Histological studies showed increased fibrous connective tissue and degenerative changes in both the striated external ${ }^{3}$ and the smooth internal sphincter muscles. ${ }^{45}$

The development of endoanal ultrasonography has revealed structural sphincter damage in up to $90 \%$ of patients presenting with incontinence. $^{6-8}$ However, there remains a proportion in whom the sphincters are intact, albeit sometimes weak. In some of these patients there is an obvious neuropathy present.

Evidence also exists to suggest that there may be an abnormality of colonic or rectal function in patients with faecal incontinence. Rectal sensation is impaired in patients with isolated neurogenic incontinence. ${ }^{9}$ In addition, external sphincter muscle recruitment during rises in intra-abdominal pressure is diminished in patients with incontinence, suggesting an impairment of sacral reflex arcs. ${ }^{10}$ The incidence of abnormally increased bowel frequency and loose bowel actions is greater in patients with incontinence ${ }^{11}$ suggesting an associated change in bowel motility, or an inability to suppress colonic activity owing to impaired sphincter function. Lastly, faecal urgency can be associated with structural damage of the external anal sphincter. ${ }^{12}{ }^{13}$ It is likely that a strong sphincter can oppose or suppress high pressure colonic activity, and that sphincter contraction may be responsible for the initiation of retrograde movement of large bowel content ${ }^{14}$ or the previously described retrograde peristalsis. ${ }^{15}$ There has, however, been no formal investigation of large bowel motility in these patients.

Twenty four hour colonic motility has been studied in the prepared bowel, ${ }^{16}{ }^{17}$ but relatively little information is available about coordinated pressure activity in the healthy unpre-
Accepted for publication 25 March 1997 
pared colon over a prolonged period..$^{18}{ }^{19}$ Our first aim was therefore to characterise this further.

We hypothesised that patients with urge faecal incontinence may have increased colonic pressure activity or an imbalance between colonic activity and the ability of the sphincter to contract. We therefore conducted prolonged ambulatory left colonic and anal motility studies in the unprepared bowel of affected patients. We also wished to investigate whether there is an alteration in colonic storage and faecal distribution in patients with incontinence, and therefore simultaneously measured the transit of intestinal contents. Lastly, we wished to determine whether there may be an abnormality of autonomic gut function which extends beyond the large bowel and anal sphincter in patients with faecal incontinence.

\section{Subjects and Methods}

PATIENTS WITH FAECAL INCONTINENCE

Six women with faecal incontinence without structural anal sphincter damage on endoluminal ultrasound were studied. None had features of irritable bowel syndrome (Rome criteria) ${ }^{20}$ or other gastrointestinal disease. Their bowel frequency was within the normal range before the study. No patient had diabetes, scleroderma, neurological or metabolic disease. None was taking any medication which could influence bowel function. Their median age was 60 years (range 50-72). The duration of faecal incontinence ranged from three to 10 years. Three patients had had a hysterectomy previously. Table 1 shows the pattern of incontinence, obstetric and other relevant history.

Faecal incontinence was classified as passive if the patient lost liquid or solid stool into their underwear without their awareness. This has previously been shown to correlate with internal sphincter weakness and damage. ${ }^{1322}$ Urge faecal incontinence was defined as incontinence occurring with the patient's awareness owing to an inability to resist the call to stool

TABLE 1 Anorectal physiological data in the study groups

\begin{tabular}{|c|c|c|c|c|c|c|c|}
\hline Subject & $\begin{array}{l}\text { Age } \\
\text { (years) }\end{array}$ & $M R P$ & $M V C$ & $\begin{array}{l}P N T M L \\
(l / r)\end{array}$ & $\begin{array}{l}\text { Electrosensory } \\
\text { threshold }(a / r){ }^{*}\end{array}$ & $\begin{array}{l}\text { Vaginal } \\
\text { delivery }\end{array}$ & $\begin{array}{l}\text { Type of } \\
\text { incontinence }\end{array}$ \\
\hline \multicolumn{8}{|l|}{$\overline{\text { Patients }}$} \\
\hline LK & 60 & 20 & 48 & $2.4 / 2.4$ & $17 / 22$ & 2 & $\begin{array}{l}\text { Urge + } \\
\text { passive }\end{array}$ \\
\hline PW & 64 & 70 & 90 & $2.4 /-$ & $12 / 49$ & 1 & $\begin{array}{l}\text { Urge + } \\
\text { passive }\end{array}$ \\
\hline $\mathrm{FH}$ & 56 & 68 & 20 & $2.1 / 2.5$ & $9 / 36$ & 2 & $\begin{array}{l}\text { Urge + } \\
\text { passive }\end{array}$ \\
\hline HW & 72 & 40 & 20 & $1.9 / 2.0$ & $5 / 9$ & 2 & $\begin{array}{l}\text { Urge + } \\
\text { passive }\end{array}$ \\
\hline DR & 50 & 24 & 60 & $2.4 / 2.4$ & $4 / 25$ & 3 & $\begin{array}{l}\text { Urge + } \\
\text { passive }\end{array}$ \\
\hline GS & 60 & 40 & 80 & $2.4 / 2.6$ & $6 / 12$ & 3 & Passive \\
\hline $\begin{array}{l}\text { Median } \\
\text { Controls }\end{array}$ & 60 & 40 & 54 & 2.4 & $7 / 23$ & 2 & \\
\hline $\mathrm{EF}$ & 39 & 115 & 30 & $2.2 / 2.6$ & $6 / 24$ & 3 & 0 \\
\hline $\mathrm{CN}$ & 56 & 80 & 80 & $2.0 / 2.1$ & $5 / 28$ & 0 & 0 \\
\hline $\mathrm{CH}$ & 55 & 70 & 115 & $1.8 / 1.8$ & $5 / 26$ & 2 & 0 \\
\hline IF & 62 & 160 & 60 & $2.0 / 2.3$ & $5 / 29$ & 2 & 0 \\
\hline PW & 62 & 92 & 40 & $2.1 / 2.1$ & $7 / 74$ & 2 & 0 \\
\hline $\mathrm{RC}$ & 45 & 60 & 50 & $2.1 / 2.0$ & $6 / 28$ & 4 & 0 \\
\hline Median & 50.5 & 86 & 55 & 2.1 & $6 / 28$ & 2 & \\
\hline
\end{tabular}

MRP, maximum resting pressure $\left(\mathrm{cm} \mathrm{H}_{2} \mathrm{O}\right)$ (normal $\left.>40\right)$; MVC, maximum voluntary contraction $\left(\mathrm{cm} \mathrm{H}_{2} \mathrm{O}\right)$ (normal >40); PNTML (1/r), pudendal nerve terminal motor latency (ms), left/right (normal <2.4).

$\star(\mathrm{mAmp})$, anus/rectum (normal $<11 / 50)$.

Normal values are derived from our laboratory. ${ }^{21}$ and reach a toilet in time. This symptom correlates best with external anal sphincter weakness or damage. ${ }^{1322}$

\section{HEALTHY VOLUNTEER CONTROL SUBJECTS}

Six women with no gastrointestinal symptoms, normal bowel habit and no history of anorectal incontinence or urgency were studied. All had a bowel frequency between three times per day and three times per week, ${ }^{23}$ and none took drugs which could have affected bowel or anal sphincter function. Their median age was 51 years (range 39-63), which was not significantly different from the patient group ( $p=0.17$, Mann-Whitney U test). Two women had had a hysterectomy previously. The control group's details are shown in table 1 .

ANORECTAL PHYSIOLOGICAL STUDIES AND ANAL ENDOSONOGRAPHY

Anorectal physiological studies were performed at least one day prior to the motility studies, according to previously published techniques. Anal manometry was performed using a water-filled microballoon station pullthrough technique ${ }^{24}$ to determine the maximum resting and voluntary contraction pressures. Pudendal nerve terminal motor latency measurements were made bilaterally using a disposable electrode (13L40, Dantec, Skovlunde, Denmark) and a nerve stimulating apparatus (Neuromatic 2000, Dantec). Anal and rectal mucosal electrosensitivity thresholds were measured using a bipolar ring electrode (21L11, Dantec) placed $1 \mathrm{~cm}$ above the anal verge, and $6 \mathrm{~cm}$ above the upper limit of the anal canal high pressure zone, respectively. ${ }^{25}$ Anal endosonography was performed using a $10 \mathrm{MHz}$ probe (B\&K Medical, Gentofte, Denmark).

Patients and volunteers were admitted to the hospital on the day prior to commencement of the study and fasted over night.

MANOMETRIC TUBE INSERTION

On the first morning subjects received a $128 \mathrm{ml}$ phosphate enema (Pharmax Ltd, Bexley, UK). After an intravenous injection of $2.5 \mathrm{mg}$ midazolam a colonoscope was advanced to the midtransverse colon or to the point where faecal loading prevented further progress. A guide wire (Amplatz type, THSF-35-260-AES, William Cook Europe A/S, Bjaeverskov, Denmark) was inserted into the bowel through the endoscope biopsy channel, and the endoscope was then withdrawn.

A flexible manometry probe $3.5 \mathrm{~mm}$ in diameter was used, which contained six solid state transducers (Gaeltec Ltd, Dunvegan, Isle of Skye, UK). The first (most proximal) transducer on the probe was located at $1 \mathrm{~cm}$ from its tip, and distances between sensors were $17.7 \mathrm{~cm}$ for the proximal three and $10 \mathrm{~cm}$ for the distal two, thereby spanning a length of $72 \mathrm{~cm}$. The probe was taped to PTFE (polytetrafluoroethylene) tubing (inside diameter $3 \mathrm{~mm}$, outside diameter $4 \mathrm{~mm}$ ) (Azlon, TWN640, Bibby Sterlin Ltd, Stone, Staffordshire, UK) to make it stiffer. 
At endoscopy, the stiffening tube was fed over the guide wire. The five proximal transducers were positioned in the colon and rectum and the most distal one in the anal high pressure zone. After insertion was complete the position of the probe was checked fluoroscopically using a freeze frame technique to minimise radiation exposure, and the transducer positions noted. Further screening was undertaken at 24 and 48 hours during the study or if the probe was partially expelled. Each screening episode was for one to two seconds, and the frozen image then used to assess tube position. The probe and supporting catheter were taped to the buttocks and the probe connected to a portable solid state recorder (UPS 2020, Medical Measurement Systems (MMS), Enschede, Holland). A sampling rate of $4 \mathrm{~Hz}$ in each of the six channels enabled 20 hours of uninterrupted data to be stored in the $1 \mathrm{Mb}$ of random access memory. The data were downloaded as required to a personal computer (IBM 486 PC) and thereafter recording was continued. This resulted in interruptions of about 20 minutes.

STUDY PROTOCOL

During the study participants were freely mobile within the hospital. They kept a written diary of their activities in addition to recording events including eating, drinking, sleeping, urge to defaecate, and start of defaecation, using specific buttons on the portable recorder. The perineal area was checked frequently and the tape re-fixed as required to keep the probe in the correct position.

Apart from the first day, when subjects fasted in the morning and received the isotope containing pancake and orange juice as lunch, a standard diet of $1890 \mathrm{kcal}$ was given. Subjects received a standard diet of breakast (cereal and toast), lunch (salad roll) and dinner (chicken with vegetables). Additional drinks were allowed ad libitum.

GASTROINTESTINAL TRANSIT

With the manometry probe in place, the gut transit study was started on the same day at midday, a minimum of two hours after its insertion. A previously described technique was used. ${ }^{26}$ Briefly, $8 \mathrm{MBq}$ of ${ }^{111}$ Indium labelled resin beads were incorporated into a $630 \mathrm{kcal}$ pancake and was used as marker for the solid phase. ${ }^{99 \mathrm{~m}}$ Technetium labelled antimony sulphide colloid (30 MBq) in orange juice was used as the marker for the liquid phase. The calculated effective dose equivalent administered for both activities amounted to $4.6 \mathrm{mSv}^{27}$

Activity of the meal was measured immediately prior to the investigation by scanning (Siemens ZLC 7500, Germany). This large field view gamma camera images the whole abdomen and was fitted with a medium energy parallel collimator and peaked for $247 \mathrm{KeV}$ and $172 \mathrm{KeV}$ with a $15 \%$ window for both energies. It was connected to a Hermes (Nuclear Diagnostics Ltd, Northfleet, Gravesend, Kent, UK) acquisition module and a work station (SparcStation 5, Sun Micro Systems, London, UK) for data storage and analysis.

Initially, the gastric emptying and small bowel transit times were determined according to previously published protocols. ${ }^{28}$ To correct for tissue attenuation, each anterior view was immediately followed by a posterior view. Data were collected in static mode for 30 seconds for each view. Scans were obtained every five minutes for the first hour, every 15 minutes for the following two hours and finally after six hours.

For large bowel scanning only the progress of the solid phase was recorded. The first colonic scans were obtained after six hours (at 1800). The second set of scans was obtained at 0900 the following morning (21 hours after the start of the study) and thereafter at hourly intervals until 1800 hours. Additional scans were taken after each defaecation. This regimen was continued on all following days until scanning ceased 69-75 hours after it began, or earlier if more than $90 \%$ of the radioisotope had been passed.

ANALYSIS OF MOTILITY RECORDINGS

Pattern analysis was performed manually using visual analysis on the computer screen by two investigators. High amplitude propagated pressure waves were defined as pressure rises with a characteristic appearance of more than $100 \mathrm{~cm}$ of water amplitude propagated over three or more transducers. Their total number in each 24 hour period, their relation to defaecation (within 15 minutes), faecal urgency, physical activity (within 10 minutes after waking up), sleeping, and eating (within 60 minutes of finishing a meal) were also noted. Events of faecal urgency entered on the portable computer by the subjects were analysed and associated motility patterns and their anatomical location recorded.

Rectal motor complexes, defined as rhythmic pressure changes recorded in the rectum, lasting more than three minutes and having a frequency between two and six per minute, ${ }^{29-31}$ were identified and their number, duration, frequency, and amplitude recorded. Rhythmic pressure changes of a similar pattern recorded from more proximal channels were similarly documented.

\section{ANALYSIS OF RADIOISOTOPE DATA}

Regions of interest were created for the stomach, small bowel and different sections of the large bowel. For each time point, to determine the true count in each region the geometric mean was calculated from anterior and posterior scans. Time-activity curves were then created for each region, expressed as a percentage of the total count. Correction was made for radioisotope decay and Compton scatter ${ }^{32}$ but not for background, as this was similar for all scans.

The rate of gastric emptying was determined for both the liquid and solid phases as previously described. ${ }^{28}$ The lag phase was determined in two ways: (i) as the time interval from the start of scanning until $5 \%$ of isotope had passed into the duodenum and (ii) as the time interval from the start of scanning to the 
first arrival of isotope in the duodenum. This was determined visually from the sequential scans. In addition, the half time for gastric emptying of solid and liquid, and the percentage of isotope left in the stomach at three hours and six hours, were determined. Small bowel transit time for solids was calculated as the time from first duodenal entry to first caecal entry. Comparisons were made between the study groups for gastric emptying for the liquid and solid phases and small bowel transit of solids.

COLONIC SCANS

Six regions of interest were created as desribed previously. ${ }^{33}$ These were caecum and ascending colon, hepatic flexure, transverse colon, splenic flexure, descending colon, and rectosigmoid.

The centre of mass of radioisotope was derived from the following formula:

Centre of mass $=($ FROI $1 \times 1+$ FROI $2 \times 2+\ldots$ FROIn $\times$ n)

where $\mathrm{F}$ denotes the fraction of counts per region of interest (ROI) and $n$ the number of the region according to the predefined sequence, from caecum (region 1) to stool (region 7). ${ }^{34}$ Comparisons were made between the two study groups for the position of the centre of mass at 24 and 48 hours.

To examine the effect of defaecation on the distribution of colonic contents, the colon was also divided into two regions, namely the right colon (up to the splenic flexure) and left colon (splenic flexure distally). The change in percentage count associated with defaecation in these two regions was calculated.

To determine whether patients with incontinence had abnormal transit or storage in different parts of the large bowel, the area under the time activity curves for each region for each patient was calculated for the time periods from $0-24,24-48$ and $48-72$ hours. These areas under the curve were calculated using digital imaging and processing software (Image, National Institutes of Health, USA). These areas were expressed in hour per cent units. Comparisons for each time period were made between patients and controls.

To determine whether the average output per bowel action was different between patients and controls, the percentage of isotope passed during each defaecation was averaged for each subject and compared between the two groups.

The study was approved by the City and Hackney Ethical Committee, and all participants gave written informed consent.

\section{Results}

ANORECTAL PHYSIOLOGICAL TESTS

Table 1 shows the anorectal physiological data for both patients and controls. The maximum resting pressure was significantly lower in patients than controls (median (range), 40 $(20-70)$ v $86(60-160) \mathrm{cm}$ water; $\mathrm{p}=0.012)$. The maximum squeeze pressures were not significantly different between the two groups. Pudendal nerve terminal motor latencies were longer in patients (2.4 (1.95-2.5) $v 2.1$ $(1.8-2.4) \mathrm{ms} ; \mathrm{p}=0.08)$. Anal and rectal sensa- tion did not differ significantly between the two groups.

Anal endosonography revealed no structural damage in any of the patients. Five controls had normal anal endosonographic findings. One healthy subject $(\mathrm{EF})$, who had two previous forceps deliveries, had a narrow external anal sphincter defect anteriorly but no internal sphincter abnormality on endosonography. This volunteer also had a normal resting pressure and borderline low squeeze pressure increment (table 1). She was fully continent.

\section{COLONOSCOPY AND PROBE POSITIONING}

Colonoscopy was well tolerated by all subjects. No pathological findings were recorded in eight studies. Of the remainder, two (one patient and one control) had sigmoid diverticula and two (both controls) had rectosigmoid adenomas. The latter completed the study and had a polypectomy at a later date.

Fluoroscopy following insertion of the manometric probe showed that the most proximal transducer was located in the transverse colon in five subjects (three patients and two controls), in the splenic flexure in three (two patients, one control), and descending colon in two (two controls). One subject in each group had a rectosigmoid study only because of a long sigmoid colon which contained the entire probe.

\section{TECHNICAL DETAILS}

The total recording time obtained during the motility studies was 506 hours, 261 in patients and 246 in controls. Individual recording times ranged from 24 to 56 hours with a median of 44 hours (median: patients 49 hours; controls 42 hours). The recording times comprised 359 hours when subjects were awake (median: patients 35 hours; controls 29 hours) and 148 hours of sleep (median: patients 13 hours; controls 14 hours).

Nine of the 12 subjects retained the probe without major positional changes of sensors as determined by fluoroscopy at 24 and 48 hours. The probe changed position in three studies. In the first patient the whole probe moved distally during defaecation and looped in the rectum after 24 hours. The loop was corrected and fluoroscopy showed that the most proximal sensor was then situated in the descending colon, and recording continued. The remainder of the probe was finally expelled during defaecation after 30 hours. As a result, a stiffer supporting tube was used in subsequent studies. Two other subjects expelled the distal two and three sensors during bowel movements at 24 and 45 hours, respectively, because of a fixation problem. Screening revealed that this led to straightening of the rectosigmoid part of the probes but only slight positional changes of the more proximal sensors, which remained in the same colonic segment.

Despite checking fixation of the perineal tape every two to three hours during the day and re-taping as required, it was almost impossible to maintain the anal sensor in the desired position, especially after $24-36$ hours due to sweating, the length and weight of the probe 

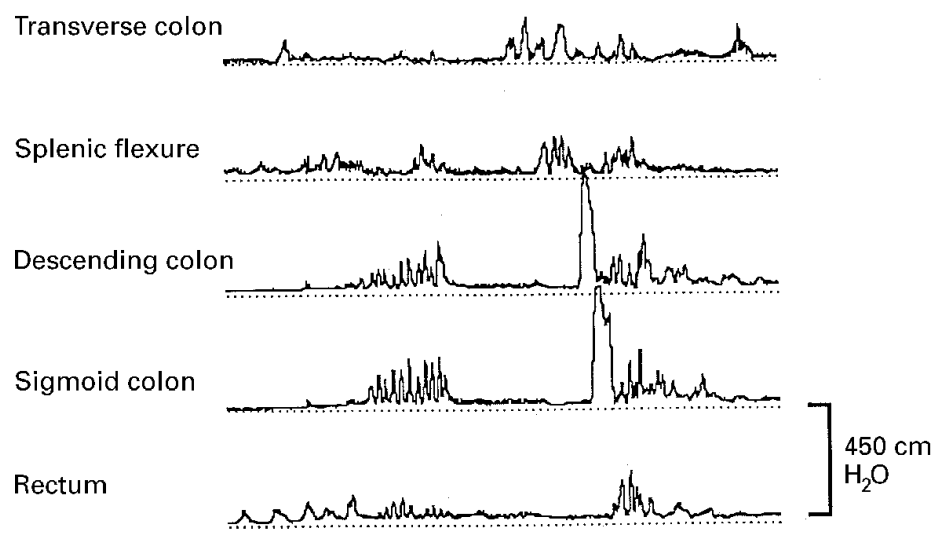

Anus

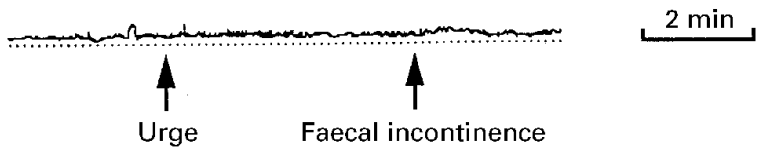

Figure 1: High amplitude propagated pressure wave (maximum pressure $470 \mathrm{~cm}$ water) in a patient, associated with urge faecal incontinence (right of the figure). The wave starts at least as proximal as the distal transverse colon and propagates as far as the rectum. The rectal pressure is $204 \mathrm{~cm}$ water. Note the lack of a protective anal pressure rise. This episode of urge incontinence was preceded by repeated high pressure rises in the rectum, sigmoid and descending colon (left of figure), which were perceived as a strong urge to defaecate.

and the fact that subjects were ambulant. Findings at perineal inspection every two or three hours were recorded in the subjects' diaries and subsequent analysis of anal motility traces was restricted to the valid periods.

Late transducer failure was a problem in studies after about 30 hours in some channels. This was mainly due to the ingress of moisture into the transducer chambers related to the hostile colonic environment, leading to electrical instability. This did not involve more than one transducer in any one study and did not prevent the accumulation of data about mass movements over several transducers.

MOTILITY ANALYSIS

Defaecation

In addition to a similar duration of the study in patients and controls, the total number of bowel movements analysed was similar for the two groups: median (range) patients $3(0-8)$, controls $4(0-8)$.

Sensation of urge to defaecate

The event button was pushed on 256 occasions to record an urge to defaecate. This was associated with high amplitude propagated pressure waves in $114(45 \%)$. Non-propagated contractions were recorded on the remaining $142(55 \%)$ occasions, and were located equally in the descending colon, descending colon and sigmoid, and sigmoid only. A small proportion ( $6 \%$ of all urge episodes) were recorded in the rectum only.

\section{Episodes of incontinence}

None of the control subjects had any incontinence. Three patients had one, two and four episodes of urge incontinence. In all three patients urge incontinence was associated with a similar pattern of associated pressure events.
High amplitude propagated pressure waves, always initially recorded from the most proximal channel (transverse colon or splenic flexure), progressed into and included the rectum. These were either single or a sequence of two or three waves. These high pressure waves were often up to $500 \mathrm{~cm}$ water in amplitude, and were highest in pressure in the descending and sigmoid colon. The rectal pressure component of this high amplitude propagated contraction was often high, at up to $250 \mathrm{~cm}$ water. The characteristics of these high pressure propagated waves which occurred in association with urge incontinence were the same, in terms of propagation of velocity and amplitude, as those which occurred in association with normal defaecation. The anal pressure response was usually low, and below that recorded in the rectum (fig 1 ).

In one patient the high pressure propagated activity was preceded by repeated regular high amplitude pressure rises occuring synchronously in the rectum, sigmoid and descending colon (fig 1). This was perceived as a strong urge to defaecate.

Three other patients had passive incontinence only. This was not associated with any detectable colonic or rectal pressure activity.

Healthy controls demonstrated identical patterns of high amplitude propagated pressure waves. These were often associated with an urge to defaecate. They were not associated with incontinence.

The anal canal pressure in association with these high amplitude propagated contractions was variable. Sometimes the pressure fell as these contractions started (fig 2). At other times the anal pressure rose or did not change. It was not possible to be certain about the anal pressure response to all colonic or rectal pressure changes, due to difficulty with retention of the anal pressure sensor precisely in the anal canal throughout the study.

High amplitude propagated pressure waves In total, 313 high amplitude propagated pressure waves were observed, 176 in patients and 137 in controls. Their minimum propagation length was $36 \mathrm{~cm}$ (observed over three transducers). Patients had a median (range) of 16 (7-21) times per 24 hours, and healthy controls had a median of $12(6-25)$ per 24 hours ( $\mathrm{p}=0.87$, Mann-Whitney U test).

When considering both groups together 69 $(22 \%)$ of these high amplitude propagated waves progressed from the most proximal sensor (transverse colon or splenic flexure) into the rectum, a total bowel length of $62 \mathrm{~cm}$. These prolonged propagated waves occurred equally in the two groups, with $30(17 \%)$ in patients and $39(29 \%)$ in controls. The median number seen per 24 hours of these long propagated waves was 2.3 (range $0-7$ ) in patients and $2.1(1-15)$ in controls.

When considering both groups of subjects most $(97 \%)$ of the high amplitude propagated waves occurred while subjects were awake. Their occurrence was related to defaecation $(27 \%)$, meals $(25 \%)$, and waking up (12\%), while in $34 \%$ there was no obvious associated 


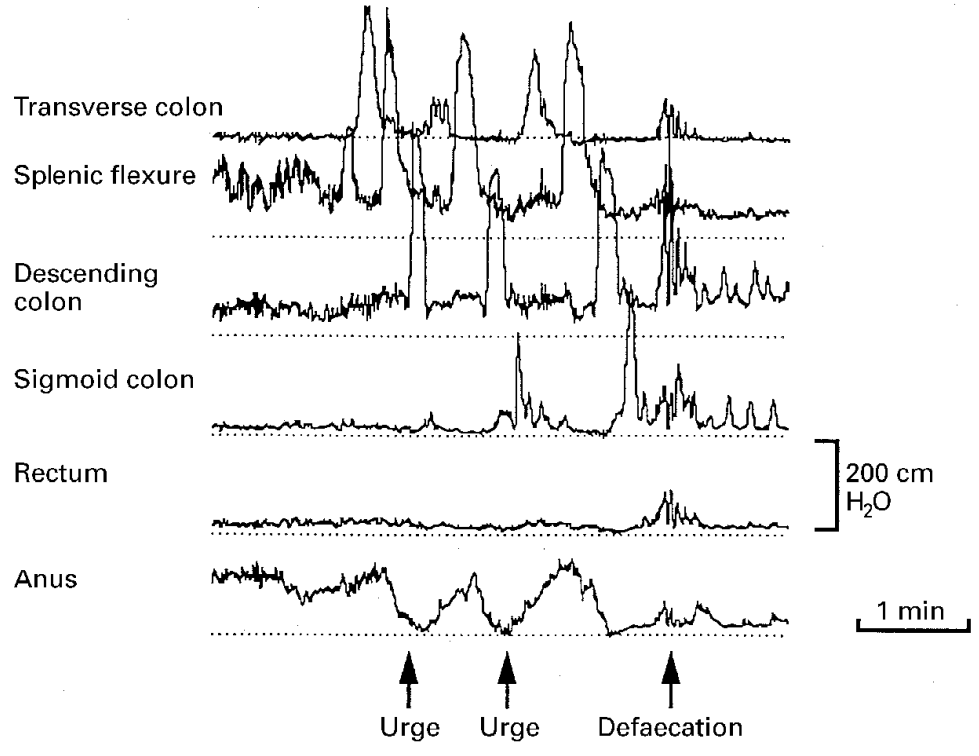

Figure 2: Repeated high amplitude pressure waves in a healthy subject associated with an urge to defaecate and the defaecation. Note the anal relaxations which occurred soon after the onset of these waves; the anal pressure was stable prior to these motor events.

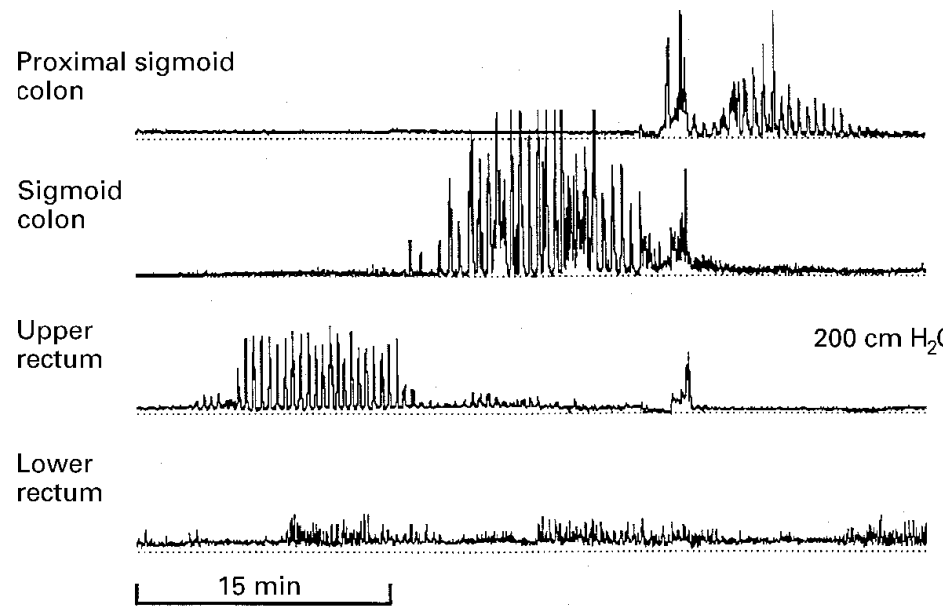

Figure 3: Rhythmic motor activity in a patient whose manometric probe was positioned in the rectum and long sigmoid colon only. The rhythmic activity, similar to previously described "rectal motor complexes", appears in this instance to be propagated in a retrograde direction. Other rhythmic activity in the left colon was non-propagated. The lowermost rectal channel may show artefactual pressure rise.

event. The associated events were similar for the two groups of subjects.

Of the 42 bowel actions, 41 (98\%) were associated with at least one preceding high amplitude contraction. The median number of high amplitude pressure waves preceding each defaecation was 2.2 (range $1-4$ ). The number was similar for the two groups. The high amplitude propagated pressure waves seen in association with defaecation were similar in their speed of propagation and amplitude to those which were not associated with defaecation. On most occasions, at least one high pressure propagated wave associated with defaecation progressed as far as the rectum.

Rectal and colonic rhythmic pressure activity Rectal motor complexes were recorded in five patients and four controls. Patients had a median of nine per 24 hours (range 1-15), compared with controls 13 (5-28). Their median duration was 15 minutes and 13 minutes, respectively. The median amplitude was $86 \mathrm{~cm}$ water and $59 \mathrm{~cm}$ water, respectively.

Similar rhythmic activity was also observed in four patients and five controls in the sigmoid colon. This was seen much less frequently than rectal rhythmic activity, being recorded 13 times in total during the entire studies in three patients and 29 times in five controls.

These events were recorded frequently in one patient who had a rectosigmoid study only. The number of such rhythmic episodes recorded per 24 hours was 21 in the proximal sigmoid, 38 in the mid-sigmoid, and 31 in the rectum. Their amplitude was higher in this patient compared with the other studies, often reaching a maximum of $250 \mathrm{~cm}$ water (fig 3). In this patient, although not in other studies, there did seem to be possible antegrade and retrograde progression of these motor complexes.

Rhythmic activity was also observed in the descending colon in two patients on three occasions in total. Their duration was eight, 11 and 16 minutes, their amplituides were 70, 80 and $120 \mathrm{~cm}$ water, and their frequency of contraction was three/minute, four/minute and five/minute.

\section{RADIOISOTOPE TRANSIT STUDY}

\section{Gastric emptying}

Gastric emptying of solids and liquids was not significantly different between the two groups, when comparing the duration of the lag phase, time for $50 \%$ gastric emptying, and percentage of isotope remaining in the stomach after three and six hours. The time for radioisotope in the solid phase to reach the caecum also did not differ significantly between the two groups.

Individual analysis of subjects compared with our laboratory normal range ${ }^{28}$ showed that all healthy controls had normal gastric emptying of liquids and solids. Three of the six incontinent patients demonstrated abnormalities of emptying: delayed late gastric emptying of solid and liquid in one patient, fast gastric emptying of solid in one patient, and slow gastric emptying of solid in one patient.

\section{Small bowel transit}

There was no significant difference between the two groups of subjects in the rate of small bowel transit.

Colonic transit

Colonic transit was not significantly different between the two groups. In particular, there was no abnormality of colonic storage. The progression of the centre of mass of the radioisotope in the colon was not significantly different between the two groups of subjects: 3 $(2.2-6.7) v 2.5$ (1.8-4.3), centre of mass, median (range), controls $v$ patients, at 24 hours; $4.7(3.7-6.5) \quad v 5.1(2.9-6.8)$ at 48 hours.

In addition, the proportion of radioisotope in each colonic segment for each of the 24 hour periods was not significantly different between the two groups of subjects. When a separate analysis was undertaken for the proportion of 
TABLE 2 Proportion of colonic contents passed and intracolonic movement of contents associated with bowel actions

\begin{tabular}{llll}
\hline Parameter & Controls & Patients & p Value \\
\hline $\begin{array}{l}\text { Stool output } \\
\text { Proportional } \\
\text { decrease (right }\end{array}$ & $23(13-87)$ & $23(9-33)$ & 0.46 \\
$\begin{array}{l}\text { colon) } \\
\text { Proportional } \\
\text { decrease (left } \\
\text { colon) }\end{array}$ & $13(10-23)$ & $24(4-41)$ & 1.0 \\
$\begin{array}{l}\text { Decrease in } \\
\text { content (right } \\
\text { colon) }\end{array}$ & $63(18-83)$ & $26(7-46)$ & 0.20 \\
$\begin{array}{l}\text { Decrease in } \\
\text { content (left } \\
\text { colon) }\end{array}$ & $25(6-51)$ & $13(3-33)$ & 0.29 \\
\hline
\end{tabular}

Results are expressed as median (range)

Stool output, percentage of original total radioisotope mass passed with each bowel action.

Proportional decrease, decrease in each colonic region occurring with defaecation, expressed as a proportion of the pre-defaecation count in that region.

Decrease in content, decreases in the count in the right and left colon after defaecation, taking the original total colonic content as $100 \%$.

${ }^{\star}$ Mann-Whitney U test.

radioisotope in the right (caecum to transverse) and left (splenic flexure to rectum) colon, the two groups did not differ significantly (all $\mathrm{p}>0.2$ ).

The percentage of stool output of radioisotope was analysed for each of 34 defaecation episodes ( 22 in patients). There was no significant difference between the two study groups (table 2).

Movements of radioisotope were determined from the immediate pre- and post-defaecation scans in 26 defaecation episodes (20 from patients). For the remainder no predefaecation scans were available, as these occurred in the early morning when subjects did not wait for a scan to be taken. Patients and controls passed a similar proportion of their colonic contents with each stool, and had a similar shift of colonic contents from the right to the left colon (table 2).

Radioisotope movement associated with episodes of urge incontinence

Radioisotope scans were available before and after urge incontinence for four of the seven episodes. In three episodes the radioisotope was in the right or transverse colon and movement within the right colon was seen in one of these episodes. In one major episode of urge incontinence $78 \%$ of the total isotope ingested was passed.

\section{Discussion}

To our knowledge there are no previous recordings of colonic motor activity which involve recordings using multiple colonic pressure ports, over a period of more than 24 hours duration, and in the relatively unprepared state. Although subjects had an enema prior to intubation, the proximal colonic contents were undisturbed and patients were studied for long enough to allow normal colonic filling. We cannot exclude that some of the obervations we recorded were influenced by the presence of a manometric tube in the colon, although previous studies in animals have suggested that the presence of an intraluminal recording device has little influence on the pattern of colonic motor activity. ${ }^{35}$ We therefore believe that this study provides new information on the pattern of colonic motor activity in healthy subjects. In addition to describing the natural frequency of high pressure propagated waves, we have characterised the changes occuring during defaecation, and have newly identified rhythmic activity proximal to the rectum. Lastly, we have related the transit of contents to motor events. These observations have been extended to patients with idiopathic incontinence.

This study has shown that in health the left colon normally demonstrates approximately 14 high pressure propagated waves over 24 hours. This number is higher than that reported in two previous studies. ${ }^{16} 36$ Both our own study and these earlier studies involved the use of colonoscopically inserted intracolonic tubes, which may affect colonic motility. The major difference therefore probably relates to the fact that our study involved the measurement of motility when the bowel contained its normal contents. A majority of high amplitude propagated waves were associated with defaecation, eating or waking, confirming the findings from a previous ambulatory study of colonic motility, ${ }^{15}$ although in this study the bowel had been prepared by purgation.

Approximately one fifth of these propagated high pressure waves progress to include all of the left colon and rectum. This number is similar to that reported in two previous studies $^{18} 19$ of colonic motility recorded using a lesser number of transducers introduced into the colon transnasally.

Defaecation was often associated with these high pressure waves propagated into the rectum. This motor sequence is identical to that reported previously in a single healthy subject, although in that case the bowel was prepared and stimulated with bisacodyl. ${ }^{37}$ The anal relaxation seen in that study, ${ }^{37}$ which occurred early in association with the colonic activity, was also seen in our study. This coordinated motor activity involving the colon and sphincter may be controlled centrally, as occurs in the oesophagus and lower oesophageal sphincter during swallowing, ${ }^{38}$ or via intrinsic neural pathways.

In the current radioisotope study normal defaecation usually involved evacuation of approximately half the left colonic contents, and was also associated with movement of right colonic contents to the left colon. In 1965 Halls ${ }^{14}$ showed, using radio-opaque markers, that defecation involves the evacuation of a variable proportion of the bowel ranging from just the rectum to the whole bowel distal to the distal transverse colon. Lubowski et a ${ }^{39}$ studied normal defaecation using orally ingested ${ }^{111} \mathrm{In}$ dium labelled DTPA. The bowel was not intubated. The mean percentage segmental evacuation which occurred during defaecation was $20 \%$ in the right colon, $32 \%$ in the left colon, and $66 \%$ in the rectum. These figures are similar to those observed in this study.

Our study has also shown that the sensation of an urge to defaecate is associated with high 
pressure propagated waves approximately half the time. The remainder of the time the same sensation is associated with high pressure contractions which are not propagated. Narducci et $a l$, in a study of prepared colon in healthy subjects using perfused manometry, have previously recognised the association of high amplitude propagated pressure waves and the sensation of an urge to defaecate. ${ }^{16}$ Many of these pressure events do not seem to be related to the movement of colonic contents, although it is possible some were associated with the transport of gas. Drossman et $a l^{20}$ studied the movement of colonic contents in association with an urge to defaecate, using ingested radioopaque markers and radiographs taken before and after the sensation. There was no apparent movement of colonic contents associated with a sense of urgency, although retrograde movement was observed if defaecation was suppressed. Crowell and colleagues, ${ }^{15}$ also using ambulatory solid state recordings, have shown that the distal bowel is capable of retrograde peristalsis. They found this motor event most commonly before bowel movements, and they may well have therefore been associated with the suppression of defaecation.

Rhythmic motor activity was observed in the rectum, similar to the "rectal motor complexes" described previously. ${ }^{29}{ }^{30}$ However, we also documented similar rhythmic activity in the sigmoid and descending colon. This activity varied in its propagation characteristics, site of occurrence, and the length of bowel over which synchronous contractions occurred. In only one patient was there possible antegrade and retrograde propagation of this activity, although this was uncertain. To our knowledge this type of rhythmic activity has not been described previously in the large bowel proximal to the rectum. Its importance is uncertain.

We observed a number of characteristic findings in patients with faecal incontinence. Urge incontinence was associated with high pressure propagated activity which did not differ from that seen in normal subjects, with or without defaecation. The difference must therefore relate to the anal pressure events associated with this bowel activity, namely an inability to oppose an increase in rectal pressure by increasing voluntary sphincter muscle activity. Previous studies in our unit ${ }^{1213}$ and others ${ }^{22}$ support this concept, and have shown that patients with urge faecal incontinence have low squeeze pressures and external sphincter damage or weakness. Unfortunately, we were unable to obtain reliable anal pressure recordings during this study, mainly because of the short anal canal and low anal pressure in patients with faecal incontinence. The probes often moved out of the high pressure anal canal zone, despite fixation to the skin and repeated checking.

Although we did not obtain enough anal recordings to make definitve comments about a lack of sphincter contractile response in incontinent patients, in at least one patient with urge incontinence we did observe strong anal contractions associated with propagated colonic pressure activity. However, the patient still experienced urge incontinence. Several factors may account for this. The anal pressure may still be lower than the very high rectal pressures we observed. In addition, there may be sensory abnormalities which lead to a late or inadequate sphincter response. In support of this possibility are the well documented sensory abnormalities in patients with incontinence without structural sphincter damage. ${ }^{9}$

Passive faecal incontinence was not associated with detectable manometric changes. This would also fit with previously published data suggesting that passive incontinence is predominantly associated with smooth muscle internal anal sphincter weakness. ${ }^{13} 22$ Clinically, this fits with the observation that passive incontinence occurs when isolated damage to the internal anal sphincter has been sustained-for example after excessive anal dilatation. ${ }^{40}$ Passive loss of stool seems to be more a phenomenon of failure to seal the anal canal, without necessary involvement of the proximal bowel.

Patients with faecal incontinence also demonstrated abnormalities of upper gut function, although these were variable. These findings raise the possibility of a more widespread involvement of disturbed extrinsic autonomic innervation. Alternatively, the inability to suppress defaecation may lead to altered intrinsic intramural or extrinsically coordinated reflexes.

We did not demonstrate an abnormality of colonic transit or storage in patients with faecal incontinence in this study. There may be several reasons for this. Transit may be normal. Alternatively, a study of a larger number of patients with passive incontinence alone, perhaps associated with loose stools and increased bowel frequency, ${ }^{11}$ may have demonstrated a problem of rectal storage. Shifts of contents are often difficult to identify accurately in radioisotope scans because they are not always associated with an absolute change in the count in a colonic region. More frequent scans may also be required to detect small movements, ${ }^{39}$ although this is impractical when studying an unpredictable event such as incontinence.

This study involved very prolonged measurement of large bowel activity in the unprepared state. It has therefore provided much new data on normal physiological activity and the physiological changes associated with normal events and abnormal symptoms. However, the colon is a relatively hostile environment, the pressures recorded are very high, and the probe is subject to considerable trauma if the subject is fully mobile. The solid state sensors are probably too expensive and not robust enough to make such studies routinely possible. The memory required on the portable recording devices also needs to be large to accommodate a long recording time from many sensors, although the sampling frequency can be lower than that required in the oesophagus, for example.

In summary, we have characterised some of the physiological changes associated with normal large bowel activity. Urge incontinence, an urge to defaecate, and defaecation can all be 
associated with identical high amplitude propagated pressure waves. Rhythmic activity seems to be present in the colon proximal to the rectum. In some patients with incontinence there is preliminary evidence for a more widespread disorder, although this requires more detailed investigation.

FH is supported by the Austrian Science Foundation (Grant J00938-MED).

1 Kiff ES, Swash M. Slowed conduction in the pudendal nerves in idiopathic (neuropathic) faecal incontinence. $\mathrm{Br} F$ Surg 1984; 71: 614-6.

2 Neill ME, Swash M. Increased motor unit fibre density in the external anal sphincter muscle in anorectal the external anal sphincter muscle in anorectal incontinence: a single fibre

3 Parks AG, Swash M, Urich H. Sphincter denervation in anorectal incontinence and rectal prolapse. Gut 1977; 18: $656-65$.

4 Lubowski DZ, Nicholls RJ, Burleigh DE, Swash M. Internal anal sphincter damage in neurogenic fecal incontinence. Gastroenterology 1988; 95: 997-1002.

5 Speakman CTM, Kamm MA. The internal anal sphincter: new insights into faecal incontinence. Gut 1991; 32: 345-6.

6 Law PJ, Kamm MA, Bartram CI. Anal endosonography in the investigation of faecal incontinence. BrF Surg 1991; 78 : 312-4.

7 Burnett SJD, Spence-Jones C, Speakman CTM, Kamm MA, Hudson CN, Bartram CI. Unsuspected sphincter damage following childbirth revealed by anal endosonography. Br f Radiol 1991; 64: 225-7.

8 Deen KI. Kumar D, Williams JG, Oliff J, Keighley MRB The prevalence of anal sphincter defects in faecal incontin $685-8$.

9 Speakman CTM, Kamm MA. Abnormal visceral autonomic innervation in neurogenic faecal incontinence. Gut 1993; 34: 215-21.

10 Womack NR, Morrison JFB, Williams NS. Anal continence depends on sphincter recruitment rather than absolute sphincter strength [abstract]. Br F Surg 1989; 76: A636.

11 Talley NJ, O'Keefe EA, Zinsmeister AR, Melton LJ. Prevalence of gastrointestinal symptoms in the elderly: a population-based study. Gastroenterology 1992; 102: 895901

12 Sultan AH, Kamm MA, Hudson CN, Thomas JM, Bartram CI. Anal-sphincter disruption during vaginal delivery. $N$ Engl f Med 1993; 329: 1905-11.

13 Engel AF, and Kamm MAK, Bartram CI, Nicholls RJ Relationship of symptoms in fecal incontinence to specific Rehincter abnormalities. Int f Colorect Dis 1995; 10: 152-5.

14 Halls J. Bowel content shift during normal defaecation. Proc $R$ Soc Med 1965; 58: 859-60.

15 Crowell MD, Bassotti G, Cheskin LJ, Schuster MM, Whitehead W. Method for prolonged ambulatory monitoring of high-amplitude propagated contractions from colon. Am Physiol 1991; 261: G263-8.

16 Narducci F, Bassotti G, Gaburri M, Morelli A. Twenty four hour manometric recording of colonic motor activity in healthy man. Gut 1987; 28: 17-25.

17 Bassotti G, Germani U, Morelli A. Human colonic motility: physiological aspects. Int $\mathcal{F}$ Colorect Dis 1995; 10: 173-80.

18 Soffer EE, Scalabrini P, Wingate D. Prolonged ambulan monitoring of human colonic motility. Am F Physiol 1989; 257: G601-6.

19 Lémann M, Picon L, Flourié B, Coffin B, Rambaud JC, Rain JD, et al. Relationship between high-amplitude propa- gated contractions and transit in the unprepared human colon [abstract]. Gastroenterology 1992; 102: A474

20 Drossman DA, Thompson GW, Talley NJ, Funch-Jensen P, Janssens J, Whitehead WA. Identification of subgroups of functional gastrointestinal disorders. Gastroenterology International 1990; 3: 159-72.

21 Jameson JS, Chia YW, Kamm MA, Speakman CTM, Chye YH, Henry MM. Effect of age, sex and parity on anorectal function. Br F Surg 1994; 81: 1689-92.

22 Delechanaut P, Leroi AM, Weber J, Touchais JY, Czernichow P, Denis P. Relationship between clinical symptoms of anal incontinence and the results of anorectal manometry. Dis Colon Rectum 1992; 35: 847-9.

23 Drossman DA, Sandler RS, McKee DC, Lovity AL. Bowel pattern among subjects not seeking health care. Gastroenterology 1982; 83: 529-34.

24 Neill ME, Parks AG, Swash M. Physiological studies of the pelvic floor in idiopathic faecal incontinence and rectal prolapse. Br F Surg 1981; 68: 531-6.

25 Kamm MA, Lennard-Jones JE. Rectal mucosal electrosensensory tests-evidence for a rectal sensory neuropathy in idiopathic constipation. Dis Colon Rectum 1990; 33: 419-23.

26 Mather SJ, Ellison D, Nightingale J, Kamm M, Britton KE. The design of a two-phase radiolabelled meal for gastric emptying studies. Nucl Med Commun 1991; 12: 409-16.

27 Stubbs JB. Letter to the Editor. Eur f Nucl Med 1993; 20: 362-3.

28 van der Sijp JRM, Kamm MA, Nightingale JMD, Britton KE, Granowska M, Akkermans LMA, et al. Disturbed gastric and small bowel transit in severe idiopathic constipation. Dig Dis Sci 1993; 38: 837-44.

29 Orkin BA, Hanson RB, Kelly KA. The rectal motor complex. F Gastrointest Motil 1989; 1: 5-8.

30 Kumar D, Williams NS, Waldron D, Wingate DL. Prolonged manometric recording of anorectal motor activity in ambulant human subjects: evidence of periodic activity. Gut 1989; 30: 1007-11.

31 Prior A, Fearn UJ, Read NW. Intermittent rectal motor activity: a rectal motor complex? Gut 1991; 32: 1360-3.

32 Horowitz M, Akkermans LMA. Scintigraphic measurement of gastric emptying. In: Read NW, ed. Gastrointestinal motilty. Which test? Petersfield: Wrightson Biomedical Publishing Ltd, 1989: 73-89.

33 van der Sijp JRM, Kamm MA, Nightingale JMD, Britton KE, Mather SJ, Morris GP, et al. Radioisotope determination of regional colonic transit in severe constipation: comparison with radio opaque markers. Gut 1993; 34: 402-8.

34 Krevsky B, Malmud LS, D'Ercole F, Maurer AH, Fisher RS. Colonic transit scintigraphy: a physiological approach to the quantitative measurement of colonic transit in to the quantitative measurement of colon

35 Cook IJ, Reddy SN, Collins SM, Daniel EE. Influence of recording techniques on measurement of canine colonic motility. Dig Dis Sci 1988; 33: 999-1006.

36 Bassotti G, Gaburri M. Manometric investigation of high-amplitude propagated contractile activity of the human colon. Am f Physiol 1988; 255: G660-4.

37 Kamm MA, van der Sijp JRM, Lennard-Jones JE. Colorectal and anal motility during defaecation. Lancet 1992; 339: 820.

38 Goyal RK, Cobb CW. Motility of the pharynx, esophagus, and esophageal sphincters. In: Johnson LR, ed. Physiology of the gastrointestinal tract. New York: Raven Press, 1987: 35991.

39 Lubowski DZ, Meagher AP, Smart RC, Butler SP. Scintigraphic assessment of colonic function during defecation. Int $\mathcal{F}$ Colorect Dis 1995; 10: 91-3.

40 Speakman CTM, Burnett SJD, Kamm MA, Bartram CI. Sphincter injury after anal dilatation demonstrated by anal endosonography. Br f Surg 1991; 78: 1429-30. 